\title{
Epistemic instrumentalism and the reason to believe in accord with the evidence
}

\author{
Nathaniel Sharadin ${ }^{1}$
}

Received: 31 May 2016 / Accepted: 6 October 2016

(C) Springer Science+Business Media Dordrecht 2016

\begin{abstract}
Epistemic instrumentalists face a puzzle. In brief, the puzzle is that if the reason there is to believe in accord with the evidence depends, as the instrumentalist says it does, on agents' idiosyncratic interests, then there is no reason to expect that this reason is universal. Here, I identify and explain two strategies instrumentalists have used to try and solve this puzzle. I then argue that we should find these strategies wanting. Faced with the failure of these strategies, I articulate a heretofore neglected solution on behalf of instrumentalism.
\end{abstract}

Keywords Epistemic justification · Epistemic reasons · Instrumentalism · Epistemic rationality

\section{Introduction: instrumentalism, intrinsicalism, and a puzzle}

Epistemologists have become interested in issues that traditionally worried their colleagues in ethics. That's because normativity and related concepts-such as the concept of a reason-show up in the epistemic domain in much the same way as in the ethical: Mary's pain is a reason to help her; equally, evidence that Mary is in pain is a reason to believe she's in pain.

In both domains we can ask what explains why one thing is a reason for another. In the practical domain: Why is Mary's pain a reason to help her? More generally: Why is there a reason to do what morality requires? In the epistemic domain: Why is evidence that Mary is in pain a reason to believe she's in pain? More generally:

Nathaniel Sharadin

natesharadin@gmail.com

1 Department of Philosophy, Syracuse University, 541 Hall of Languages, Syracuse, NY 13244-1170, USA 
Why is there a reason to believe in accord with the evidence? This latter question, about the reason there is to believe in accord with the evidence, is a question about the source of normativity of epistemic reasons. An answer to this question explains why, epistemically speaking, evidence matters: it explains why facts about what is evidence for what constitute, or ground, facts about what we have reason to believe. An answer to this question is a core component of a complete theory of epistemic normativity. ${ }^{1}$

There are two answers to this question in the literature. The first, instrumentalism, says that there is a reason to believe in accord with the evidence because doing so is an instrumentally rational way of achieving the ends, goals, or interests one has. ${ }^{2}$ According to instrumentalists about epistemic normativity, epistemic normativity is a species of practical normativity. What explains the reason to believe in accord with the evidence is a more general, non-epistemic, practical requirement to take the means to one's ends, believing in accord with one's evidence being one instance of such a means. Intrinsicalism disagrees. According to intrinsicalists, the reason there is to believe in accord with the evidence is independent from any relationship doing so bears to one's ends, goals, or interests. Instead, says intrinsicalism, it's a brutely epistemic normative truth that there is a reason to believe in accord with the evidence. ${ }^{3}$ So, rather than being a species of practical normativity, epistemic normativity is, on this view, a sui generis species of normativity. 4

Instrumentalists face a puzzle. To see the puzzle, distinguish between reasons that are universal in their scope ('universal reasons') and those that are not ('particular reasons'). Universal reasons are reasons for all agents. Intuitively, the fact that Mary is in pain is a universal reason to help, since it is a reason for any agent to help. Particular reasons are not reasons for all agents. Intuitively, the fact that the Mets are in the playoffs is a particular reason to purchase tickets to the game, since it is a reason only for a proper subset of agents, viz., those whose interests would be served by seeing the Mets play.

The reason there is to believe in accord with the evidence appears to be, just as the reason there is to help Mary appears to be, a universal reason: a reason for all agents. Unlike the reason there is to purchase Mets tickets, the reason to believe in accord with the evidence doesn't seem to apply only to a proper subset of agents. ${ }^{5}$ The puzzle for instrumentalism is that it is hard to see how this could be true if instrumentalism were correct. After all, according to instrumentalism the reason there is for any particular agent to believe in accord with the evidence is grounded in the fact that doing so is an instrumentally rational way of achieving the ends, goals, or interests that particular agent actually has. But agents can of course have radically idiosyncratic ends, goals,

\footnotetext{
1 For a nice articulation of this question in the practical domain, see Dreier (2015).

2 Kornblith (1993, 2002), Stitch (1990), Papineau (1999, 2009), Steglich-Petersen (2006, 2008), Grimm (2008, 2009) and Street (2009, 2008).

3 Kelly (2003, 2007), Wedgwood (2007) and Parfit (2011).

4 Cowie (2014) divides the field in much the same way. I follow Cowie in ignoring, for present purposes, a version of epistemic error theory according to which, contrary appearances, there are no reasons for belief and so, a fortiori, no reason for believing in accord with the evidence. For a defense of such a view, see Olson (2011) and Streumer (2013). For criticism, see Cuneo (2007).

5 This is also how Schroeder (2007) characterizes universality in reasons.
} 
and interests. And we can imagine an agent whose idiosyncratic interests would not be promoted by believing in accord with the evidence. For instance, it's easy to imagine an agent who would only be devastated were she to come to believe, what the evidence supports, that a friend has betrayed her, or that she will shortly die from a terminal illness, and who does not have any interests that are frustrated by believing, contrary to the evidence, that her friend is loyal, or that she herself is the picture of good health. It appears, at least if the situation is understood so that the agent really has no interests that would be promoted by believing in accord with the evidence that her friend remains loyal or that her lifespan should still be measured in years rather than days, that on the instrumentalist view of things such an agent would lack any reason to believe in accord with her evidence. But if the reason to believe in accord with the evidence is universal, then this is not so: the reason there is to believe in accord with the evidence would still be a reason for our imagined agent to believe in accord with her evidence. How could this be?

Instrumentalists therefore face an explanatory puzzle. I'll call this explanatory puzzle the Universality Challenge, and it's useful to think about it as an inconsistent triad:

1. The reason to believe in accord with the evidence is a universal reason.

2. The reason to believe in accord with the evidence is an instrumental reason.

3. Instrumental reasons are never universal reasons.

The puzzle is sometimes trotted out by intrinsicalists as evidence that the instrumentalist picture has got something wrong, and therefore as a point in favor of intrinsicalism. ${ }^{6}$ Since intrinsicalists reject (2), there's no problem-at least no prima facie problem of the sort facing instrumentalism-in making sense of the claim that the relevant reason is universal. Cards on the table: I'm an instrumentalist. My aim in this paper is to argue that instrumentalism has a satisfactory response to the Universality Challenge. Actually, things are more complicated than that: First (Sect. 2), I'll identify and explain two different strategies instrumentalists have used to try and respond to the challenge. As we'll see, both strategies are ways of rejecting (3). I'll explain both why neither of these solutions works and also why these two strategies seem to exhaust the possibilities when it comes to rejecting (3). This constitutes my peace-offering to intrinsicalists: I'll show why they are justified in complaining that, to date, instrumentalists have no good response to the Universality Challenge. Faced with the failure of these strategies, I'll recommend the instrumentalist change tack (Sect. 3): rather than rejecting (3), she should reject (1). In brief, I'll argue that while the two strategies discussed in Sect. 2 fail to deliver a vindicating explanation of the intuition that the reason to believe in accord with the evidence is universal, they can be used in a particular non-vindicating explanation of the same. As I'll explain (Sect. 4), I think this solution to the puzzle - an explanation for why we think and act as if (1) is true despite its not being so-might be acceptable to at least some epistemic intrinsicalists. At worst, then, I'll be doing two things in this paper: explaining why extant strategies for answering the Universality Challenge on behalf of instrumentalism fail and offering a novel, heretofore neglected strategy of reply to that challenge. At best, I'll

${ }^{6}$ C.f. Kelly (2003). 
do these two things and convince (some) intrinsicalists to give up their intrinsicalist ambitions. Intrinsicalists unshakeable in their convictions are invited to skip the final two sections, read the paper as an attack on extant instrumentalist strategies, and then file it away under reasons-I-am-not-an-instrumentalist.

\section{Responses to the universality challenge: two strategies for rejecting (3)}

\subsection{The special interests strategy}

It's useful to divide extant attempts to respond to the Universality Challenge into two strategies. Both, as we'll see, are different ways of rejecting (3): the claim that instrumental reasons are never universal reasons.

According to the first strategy, the Special Interests Strategy, there are special epistemic interests that all agents possess. ${ }^{7}$ The idea, then, is that the interests on which the reason to believe in accord the evidence depends are these special epistemic interests and that, because all agents possess these interests, the reason to believe in accord with the evidence is suitably universal. Examples of this idea abound. Richard Foley, for instance, seems to have something like this view in mind when he claims that the fundamental epistemic interest agents have is to "now believe those propositions that are true and now not to believe those propositions that are false". 8 Similarly, Laurence BonJour holds that "the goal of our distinctively cognitive endeavors is truth: we want our beliefs to correctly and accurately depict the world". ${ }^{9}$ William Alston has the same idea in mind, when he says that "the products of our cognitive activities can be better or worse vis-a-vis the goals of cognition," and goes on to endorse an account of what those goals comprise that is in all relevant respects the same as Foley and BonJour's. ${ }^{10}$ Other epistemologists disagree over what the content of these epistemic interests, goals, or ends is (or ought) to be. Perhaps the relevant epistemic or cognitive interest is not in truth but in knowledge or understanding or in something else altogether. ${ }^{11}$ But the idea in all these cases is the same: because all epistemic agents have the same epistemic goals or interests, the reason there is to believe in accord with the evidence, despite being grounded in agents' interests as instrumentalists think it is, is universal.

\footnotetext{
7 Here I draw on and extend an argument I make in my Sharadin (2015b).

8 Foley (1987, p. 8).

9 BonJour (1985, p. 7).

10 Alston (2005, p. 29). It may be that Foley, BonJour, and Alston would each reject a characterization of their views as instrumentalist and instead view their account of the special epistemic interests agents have simply as an a la carte addition to their intrinsicalism. That is not important at present. What is important is the suggestion, made by Foley, BonJour, Alston, and others, that there are these special epistemic interests: that is the hinge on which the Special Interests Strategy on behalf of instrumentalism tries to turn. Whether or not Foley, et. al would themselves count as instrumentalists isn't relevant. If they are right that agents have these special epistemic interests, then the instrumentalist is free to make use of those interests in responding to the Universality Challenge.

11 See for instance Kvanvig (2003, 2005), Brogaard (2009) and Grimm (2008).
} 
The problem with the Special Interests Strategy is that it's hard to credit the claim that all agents, all of the time, possess these special, yet very general, epistemic ends and interests. Notice that in order to be successful as a response to the Universality Challenge, the Special Interests Strategy needs to hold not just that agents are interested, more often than not, in believing the truth about particular propositions. It must also hold that all agents are interested, all of the time, in believing the truth full stop (i.e., about any proposition whatever). For it is only if this latter claim is true that the reason to believe in accord with the evidence will turn out to be universal. It's only if agents have a special, fully general epistemic interest in, say, truth that there is a reason for all of their beliefs (and not just ones of particular import) to be responsive to evidence of truth. If the Special Interests epistemic agents have are more particular, limited to believing truly about (or knowing, or understanding) this or that proposition, then the reason to believe in accord with the evidence will be correspondingly particular. But, again, it is hard to see why we should think this is true of actual agents - that is, of agents like us. As Thomas Kelly points out, there are "very real limits to how wide even the widest of my cognitive goals are." ${ }^{2}$ He continues:

Whether Bertrand Russell was right- or left-handed, whether Hubert Humphrey was an only child - these are matters of complete indifference to me. That is, I have no preference for having true beliefs to have no beliefs about these subject matters; nor, for that matter, do I have any preference for having true beliefs to false beliefs. There is simply no goal—cognitive or otherwise-which I actually have, which would be better achieved in virtue of my believing true propositions about such subjects, or which would be worse achieved in virtue of my believing false propositions about them. ${ }^{13}$

Kelly's self-report seems accurate. But whatever credence we give to Kelly's report, at the very least it seems we must admit that it is in principle psychologically possible for an agent to lack any general interest in truth. ${ }^{14}$ If we refuse to admit the possibility of such an agent, we shall start to lose our grip on what is supposed to be meant by the Special Interests Strategy's claim that the epistemic interests are the kind of psychological attitude that ground the reason to believe in accord with the evidence. They begin, instead, to look like a theoretical posit stipulated simply to do the job of establishing that this reason is universal, and we find ourselves tracing a very small circle.

To explain: The instrumentalist says that the reason to believe in accord with the evidence is grounded in our interests. An explanatory challenge arises: Why, if this is so, is that reason universal? After all, individuals' interests can and do often vary. Universality is secured, the Special Interests Strategy explains, because agents all share a special epistemic interest in common. But in the face of apparent counterexamples to this claim, such as the one Kelly reports, it cannot be acceptable to reply that these cases are impossible, and that we know they are impossible because the reason is

\footnotetext{
12 Kelly (2003, p. 624). See also Lynch (2009).

13 Kelly (2003, p. 625).

14 C.f. David (2001, p. 155), who points out that this idea, that agents have a standing desire for true rather than false beliefs, is a "somewhat daring empirical claim about human psychology."
} 
universal-and, moreover, its being universal rules out, because of the instrumentalist account, such cases. That sort of reasoning isn't just circular, it's dizzying.

It's worth pausing for a moment over this dialectic and comparing it to the analogous dialectic in the case of morality. Faced with a moral version of the Universality Challenge, the moral instrumentalist might appeal to something much like the Special Interests Strategy. Why, despite depending on our interests, is the reason there is to do what morality requires a universal reason? Because, says the moral version of the Special Interests Strategy, practical agents' interests are not completely idiosyncratic. Instead, there are some things that all agents care about: respect, the general happiness, acting only on reasons all could endorse, or whatever, and the reason to do what morality requires is grounded in one of these. Hence the reason to do what morality requires, though it is grounded in agents' interests, is universal, since there are some facts about some interests that all moral agents have. The correct response to this strategy in the moral case is, of course, to point out the possibility of Hume's Sensible Knave, or Shakespeare's Iago, or any number of other agents that appear to lack the relevant interest that is supposed to ground the universal bonafides of the reason to do what morality requires. In effect, that is what Kelly is doing on the epistemic side of things in reporting his own lack of a general interest in truth: he is epistemology's Iago. Stipulating that agents do have the relevant interest simply assumes, rather than explains, why it is that the reason to believe in accord with the evidence is universal. The Special Interests Strategy won't work. ${ }^{15}$

\subsection{The modal strategy}

This brings us to the second strategy, pursued by instrumentalists, for answering the Universality Challenge. ${ }^{16}$ I'll call this strategy the Modal Strategy, and we'll see why that name is apt in just a moment. According to the Modal Strategy, it is a mistake to look for some special epistemic interest shared by all agents on which to ground the universality of the reason to believe in accord with the evidence. Instead, according to this strategy, we should focus on the role played by beliefs that accord with the evidence in promoting our interests whatever those interests might be. Hence Modal

\footnotetext{
15 There is a familiar rejoinder to this worry with the Special Interests Strategy in both the epistemic and the moral case: the Constitutivist Gambit. According to the Constitutivist Gambit, contra appearance, it is impossible for there to be epistemic or moral agents of the sort described by Kelly, Hume, and Shakespeare, and this is because part of what it is to be an agent of the relevant sort involves having the relevant special interest. For examples of the Constitutivist Gambit, see Korsgaard (2009, 1999), Velleman (1989, 2000), Rosati (2003) and Smith (2013). The Gambit is subject to its own set of problems: for criticism, see Schroeder (2007), Katsafanas (2011), Tiffany (2011, Chap. 6) and Enoch (2006, 2011), and for replies, see Ferrero (2009) and Silverstein (2015). For my part, I find these criticisms convincing: I worry, with David Enoch, that the Constitutivist Gambit deprives instrumentalism of one of its most attractive features, viz., the ability to answer questions about the authority of some domain of normativity with ease. But in any case, exploring this line of argument would take me too far afield here. So I'll leave it at that. If you're more optimistic than I am about the prospects for constitutivism, the remainder of the paper can be read conditionally, as an exploration of what the instrumentalist should say, given that the Constitutivist Gambit can't be made to work. This exploration is worthwhile, since a range of people on both sides of the issue - that is, intrinsicalists and instrumentalists are, like me, pessimistic about the Gambit.

16 Here I draw on and extend an argument I make in my Sharadin (2015b).
} 
Strategy: if it works, this strategy secures the universality of the reason to believe in accord with the evidence in any possible world where agents have interests, not just in the actual world where they may (or may not-see above) have some special epistemic interests. $^{17}$

This idea, that beliefs in accord with the evidence promote our interests, whatever those interests might be, appears to have first been suggested in this context, albeit only tentatively, by Robert Nozick:

Truth, then, would be rather like what John Rawls has called a primary good, something that is useful for a very wide range of purposes-almost all-and hence will [...] bring benefit (almost) no matter what our particular purposes might be. ${ }^{18}$

The idea, then, is that because true beliefs are useful for a wide range of purposes, and because beliefs that accord with the evidence are more likely to be true, there's a reason to have beliefs that accord with the evidence "(almost) no matter what our particular purposes might be." But Nozick is careful to hedge: almost all purposes, he says, will be furthered by having true, rather than false, beliefs. But almost all is not sufficient for the instrumentalist who wants to guarantee that the reason to believe in accord with the evidence is universal, rather than particular. For the fact that almost all our purposes are served by having true, rather than false, beliefs only shows that the reason to believe in accord with the evidence is, correspondingly, almost universal. So the proponent of the Modal Strategy as a response to the Universality Challenge must go further: she must hold that, as a matter of fact, beliefs that accord with the evidence always further our interests, whatever those interests might be. And that is precisely what some instrumentalists have done. For example, Hilary Kornblith argues that the reason to believe in accord with the evidence is explained in terms of our interests but is nonetheless universal because, whatever things we in fact care about, we shall need to make various cost-benefit calculations in order to successfully pursue those things. ${ }^{19}$ But in order for such cost-benefit calculations to be capable of successfully guiding us to the achievement of what we actually care about, those cost-benefit calculations shall need to be working with accurate, evidentially-responsive representations of the way the world is rather than inaccurate, evidentially-unresponsive representations of the world. To see Kornblith's point, consider one of his examples:

In choosing between [...purchasing] two toasters [...] we must figure out the consequences of the two purchases; we must assign values to each of them; we must do some arithmetic. If we performed this calculation by using a cognitive system which gave us true beliefs, we would thereby be informed about the actual consequences of purchasing each toaster, what it is we actually value, and the extent to which these consequences actually produce those things we value.

\footnotetext{
17 Thanks to an anonymous referee for recommending more clarity on this point.

18 Nozick (1993, p. 68).

19 Kornblith (1993, 2002).
} 
We would thus come to know which toaster better serves our interests, whatever those interests may be. ${ }^{20}$

Kornblith's point is not meant to be restricted to toasters. Instead, the idea is that, whatever we care about, in order to successfully acquire, promote, or achieve it, we shall need to have accurate representations of the way things stand in the world. So, according to the Modal Strategy, it is not that we have some special epistemic interest (e.g., in truth) that grounds the universality of the reason to believe in accord with the evidence. Instead, our particular, non-epistemic interests, whatever these might be, ground the universality of that reason because beliefs that accord with the evidence promote our interests, whatever they might be. Hence we get, as Kornblith says, an instrumentalist "account of the source of epistemic normativity, but an account which is universal.",21

Kornblith isn't alone in thinking the Modal Strategy is promising. Mark Schroeder toys with the idea too, though he doesn't quite endorse it. ${ }^{22}$ Although he doesn't endorse it, Schroeder's articulation of the strategy is instructive. Here is how he explains the idea: there are some propositions such that believing truly about those propositions promotes an agent's interests, whatever the specific content of the agent's interests might be. This much is uncontroversial, as Kornblith's example of choosing between toasters nicely illustrates. And while there are many propositions believing the truth about which does not seem to promote an agent's interests, believing falsely about these propositions can lead the agent into error about other propositions. And similarly for those other propositions: believing falsely about those other propositions might lead an agent into error about still further propositions. But then, given a "relatively weak assumption about the holism of belief formation," this means that an agent's believing the truth about any given proposition will promote-at least to some degree-an agent's interests, no matter what their content. ${ }^{23}$ This is because believing the truth about any given proposition promotes believing the truth about other propositions which in turn promotes believing the truth about still further propositions, which in turn .... and so on until we get to propositions believing the truth about which promotes directly the satisfaction of any given specific interest. ${ }^{24}$

Notice that however we tell it, this story is suitably general while avoiding the difficulties associated with the Special Interests Strategy. Its success does not depend on thinking that all agents all of the time have some specific epistemic ends or interests that are promoted by believing in accord with the evidence. Instead, it only depends on thinking (1) that for any interest whatever, there are some propositions such that believing truly about those propositions promotes those interests; (2) believing in accord with the evidence makes one more likely to have true rather than false beliefs;

\footnotetext{
20 Kornblith (1993, pp. 370-371).

21 Kornblith (1993, p. 373).

$22 \mathrm{He}$ does come close to endorsing this strategy in the case of moral instrumentalism, though even there he is careful to hedge. See Schroeder (2007, p. 113, fn. 16).

23 Schroeder (2007, p. 114).

24 Schroeder (2007, pp. 113-114). Kate Nolfi pursues a modified version of this strategy in her Nolfi (2015).
} 
and, as Schroeder puts it, (3) that "a relatively weak assumption about the holism of belief formation" is true. ${ }^{25}$

How successful is the Modal Strategy? Let's begin with (1), the claim that for any interest whatever, there are some propositions such that believing truly about those propositions promotes those interests. This claim strikes me as uncontroversially true. Consider that interests-desires, wants, projects, and their ilk-are attitudes with a world-to-mind direction of fit; that is, rather than purporting to represent the way the world actually is, they are, roughly, representations of ways one wants the world to be. ${ }^{26}$ Successfully pursuing an interest-whatever its specific content-involves manipulating the world to come into conformance with how one wants things to be. But it should be clear that for any given interest, there are at least some propositions believing truly (as opposed to falsely) about will help one in this sort of pursuit. Suppose you desire to eat a salty treat, you have two treats - one in each hand - and you can only eat one treat. At the very least, believing truly that the treat in your right hand is not salty and the treat in your left hand is salty promotes the satisfaction of your desire. The claim made in (1) is therefore very weak indeed, and in any case I think we should grant it to the proponent of the Modal Strategy.

What about (2)? Notice why the Modal Strategy needs this claim. Recall that we're interested here in whether the Modal Strategy can successfully explain the universality of the reason there is to believe in accord with the evidence. Together with (3) - more on this in a moment-(1) goes some way toward showing that there is a universal reason to have true rather than false beliefs. After all, true (as opposed to false) beliefs seem to promote our interests, whatever those interests might be. But in order to show that this discovery bears on whether the reason there is to believe in accord with the evidence is universal, we need a kind of bridge principle taking us from evidence to truth. (2) is such a principle. I'm not interested, here, in arguing over whether (2) is the correct principle about how evidence relates to truth, how that connection works, or why. ${ }^{27}$ Instead, I suggest, like (1), we simply grant (2) to the proponent of the Modal Strategy.

The problem with the Modal Strategy is that the "relatively weak" assumption about the holism of belief formation (3) is actually not all that weak, and probably not true. We've just granted that there are some propositions believing the truth about promotes the satisfaction of an agent's interests, whatever those interests might be. But in order for the Modal Strategy to be successful it must be true, of each and every proposition an agent might come to believe, that believing the truth about that proposition promotes - in the sense of makes it more likely than otherwise ${ }^{28}$ - the successful achievement

\footnotetext{
25 Schroeder (2007, p. 114).

26 This is not meant to be a commitment to analyzing interests in terms of direction of fit, only a useful way of illustrating the point. For criticism of the direction of fit metaphor as a device for analyzing interests (and indeed beliefs), see Frost (2014).

27 For a detailed discussion of these issues, see Achinstein (2003).

28 What it means to 'promote' a desire or interest, and in particular whether promotion is always a matter of probability increasing, is a matter of some controversy. See, for example, my Sharadin (2015a, 2016), Dellsén and Sharadin (unpublished), Snedegar (2014), DiPaolo and Behrends (2015), Lin (2016), Coates (2014) and Behrends and DiPaolo (2011). But in order to have some account to be getting on with, I assume a roughly probabilistic account of promotion.
} 
of her interests, whatever these turn out to be. In other words, we must be able to draw a line-however meandering and crooked - between believing truly about any arbitrary proposition $P$ and successfully achieving some interest $I$ the agent actually possesses. The assumption about the holism of belief formation we need to make to guarantee that in any arbitrary case we can sketch such a line is quite strong indeed. The "web of belief" metaphor is helpful here. We must assume that each and every proposition is such that, were it to be falsely believed, it would have a run-on effect in terms of making it more likely to have false beliefs throughout the web of an agent's beliefs, and in particular more likely to have false beliefs in propositions believing the truth about which would directly promote the satisfaction of an agent's interests, whatever their content. This is not a weak assumption, and it probably isn't true.

Consider the proposition $N$ : "It rained in Paris on Napoleon's 22nd birthday". $N$ is either true or false: either it rained in Paris on that day, or it didn't. Suppose it didn't, but that I wake up one morning and, without any evidence, find myself believing that it did rain in Paris on that day. So, I have a false belief and, moreover, a belief that's not in accord with my evidence. The "weak" assumption we are being asked to make by the Modal Strategy is that my having this belief will somehow affect whether I have true beliefs the having of which promotes some actual interest of mine. This is incredible. We can canvass my interests to look for plausible candidates. I'm not sure what the proponent of the Modal Strategy would say the relevant interest would be, but let's just pick some arbitrary interest of mine and see whether believing truly about $N$ plausibly promotes believing truly about some propositions believing the truth about which promotes the interest or which promotes believing truly about some propositions [... and so on]. I just woke up, so I'm likely interested in right now getting a coffee. Does believing truly about $N$ either directly promote that interest or promote believing truly about some propositions true belief about which [...] would promote that interest? It seems not. If I'm interested in right now getting a coffee, I shall need to truly believe things about coffee, filters, money, which coffee shops are open, and so on. I am at a total loss for seeing any reason for thinking that this_-admittedly wacky-belief of mine regarding the miserable conditions in Paris on Napoleon's 22nd will affect the likelihood of my having true beliefs about such matters and so affect the satisfaction of my interest in right now getting coffee. The point is even clearer if we suppose that my false belief that $N$ only hangs about for a few minutes: I find myself believing it, then, after reporting it to a colleague, she shows me irrefutable evidence to the contrary, and I cease to believe $N$. Why should we think, during the short interval that I falsely, and without any evidence, believed $N$, that a true belief would have served me any better in pursuit of what I cared about, viz. right now getting a coffee?

Of course, the proponent of the Modal Strategy might say that it's not my interest in right now getting coffee that is promoted by believing truly about $N$, but instead some other interest of mine. Note that this interest must not be some special epistemic interest of mine- that would make the Modal Strategy collapse into the Special Interests Strategy. But what could this interest possibly be? And, moreover, why should we think I have it? It certainly seems possible to lack any interest in something that true belief about $N$ either directly promotes or which is promoted by believing truly some other proposition true belief about which true belief in $N$ itself promotes or [...]. But 
the denial of this claim is what the Modal Strategy needs in order to be successful. It needs to claim that we can always draw a line-however crooked and meanderingbetween true belief about $N$ during a possibly short interval and my believing truly about some propositions that affect my pursuit of my actual interests during that same interval. How do we draw this line? Worse: Why should we think there's always some actual interest of mine at one end of it? I honestly don't know where to begin to answer these questions on behalf of the Modal Strategy: the supposition that always, everywhere, true belief promotes (either directly or indirectly) the satisfaction of some actual interest of an agent strikes me as something we have no reason to accept, and so a decisive reason for rejecting the Modal Strategy.

\section{Changing tack: a non-vindicating explanation of (1)}

\section{Recall our inconsistent triad and its attendant puzzle:}

1. The reason to believe in accord with the evidence is a universal reason.

2. The reason to believe in accord with the evidence is an instrumental reason.

3. Instrumental reasons are never universal reasons.

What the Special Interests and Modal Strategies have in common is their aspiration to solve this puzzle by rejecting (3): both attempt to explain how it is that the reason to believe in accord with the evidence is universal, despite the fact that this reason fundamentally depends on agents' interests. As we just saw, the Special Interests Strategy attempts to do so by identifying special epistemic interests, whereas the Modal Strategy attempts to do so by explaining how according beliefs to the evidence is related to the promotion of non-epistemic interests, whatever these might be. Neither strategy appears to be successful. The Special Interests Strategy appears liable to counterexamples: not all agents have the relevant interests, and stipulating that they do appears to assume, rather than explain, the universality of the relevant reason. The Modal Strategy also appears liable to counterexamples, or else it requires an unconscionably strong hypothesis about the holism of belief formation.

I am not aware of any attempts by instrumentalists to answer the Universality Challenge that do not amount to pursuing one of these two strategies. And notice that in attempting to answer the Universality Challenge the instrumentalist who wants to hold on to (1) and (2) has limited resources available to her: in order to reject (3) she will need to show that the reason to believe in accord with the evidence, despite depending on agents' interests, is universal. But in order to establish this she will either have to show that (a) there are some universal interests or (b) evidentially supported belief bears some universal relationship to interests, whatever their content. In effect, the Special Interests and Modal Strategies represent attempts to pull off (a) and (b), respectively.

If rejecting (3) won't work, then what's an instrumentalist to do? I think the instrumentalist should give up her ambition to provide a vindicating explanation of the universality of the reason to believe in accord with the evidence, i.e., an explanation according to which it's true that there is such a reason. Instead, I think she should offer a non-vindicating explanation of the reason: she should explain why it is that we think the reason is universal, despite its not being so. In other words, she should provide an 
explanation of our strong intuition that there is a universal reason to believe in accord with the evidence, but not one that vindicates the existence of such a reason. In other words, she should reject (1): she should give up the idea that the reason to believe in accord with the evidence is universal. And in order to soften the blow, she should accompany this rejection with an explanation of why we might have thought that (1) is true. ${ }^{29}$

To ease into this idea, we can go back and think about how the Universality Challenge arises in this context. It arises, in the first place, from the observation that our practice of epistemic evaluation - our practice of evaluating our own and others' beliefs - appears to be insensitive to variations in our own and others' interests. For instance, suppose you and I differ in our non-epistemic interests with respect to $P$ - say, you care a lot about whether $P$ and, for me, $P$ is a matter of relative indifference. This fact appears not to make any difference to how we think it is epistemically rational for each of us to respond to evidence regarding $P$. If Jim, a reliable source regarding $P$, tells us both that $P$, there appears to be a reason for you to believe that $P$ and a reason for me to believe that $P$, and our relative interests in $P$ seem to have nothing to do with the matter. ${ }^{30}$ Or consider claims concerning what is and what is not epistemically rational to believe. When I say it would be irrational to believe the Apollo 11 moon landing was faked, I do not take myself to mean that it would be irrational to believe the Apollo 11 moon landing was faked for someone with a set of interests that is relatively similar to my own. It's simply wrong to think that, when I say that believing the moon-landing was a well-executed hoax is irrational, I mean my claim about irrationality to be restricted in any way to certain individuals. I mean it's epistemically irrational, full stop.

More generally, we do not treat agents as able to dodge their epistemic obligations and responsibilities by citing the lack of certain interests or the possession of contrary interests. This fact, that one isn't able to plead disinterest in order to excuse oneself from the reason there is to believe in accord with the evidence, appears to support the claim that such a reason is universal. For when reasons are not universal-that is, when they are particular-it is usually sufficient to cite something or other to show that the reason does not apply to one. And when reasons are not universal and have an instrumental character, it is usually sufficient to cite one's disinterest in something or other to show that that the reason does not apply to one. For instance, if you are playing chess and I tell you that there is a reason for you to now castle in order to avoid checkmate in two moves, you could reasonably reply that you're sick of playing, and that the prospect of checkmate is quite welcome. But this just isn't the case with respect to epistemology: there appears to be a reason for agents to conform their

\footnotetext{
29 A related issue, but one I can't address here for reasons of space, is the apparent need for the instrumentalist to then go on to provide (or co-opt) some conception of evidence that is non-normative, i.e., according to which it can be the case that $\mathrm{E}$ is evidence that $\mathrm{P}$ and simultaneously the case that $\mathrm{E}$ is not a reason to believe P. This is an issue raised in Kelly (2007). Here, I note only that part of such a non-normative account of evidence would, if the instrumentalist takes the tack I am here recommending she take, include a non-vindicating explanation of our commitment to the normative conception of evidence. In other words, an explanation of why we are discinclined to go around denying that the fact that if something is evidence then it is also a reason to believe. Thanks to an anonymous referee for urging clarity on this point.

30 Compare Kelly (2003, p. 624).
} 
beliefs to the evidence whatever they happen to care about. This is what gives rise to the Universality Challenge to instrumentalism: How, if the reason to believe in accord with the evidence is instrumental in character, can that reason nonetheless be universal in the way it so manifestly appears to be? Instrumentalism owes us an explanation.

What I am now going to insist on is that, faced with the failure of the Special Interests and Modal Strategies, instrumentalism should give up its ambition to provide a vindicating explanation of the universality of the reason to believe in accord with the evidence. Instead, what instrumentalists should do is provide an explanation of why we might come to treat that reason as if it were universal, despite the fact that it isn't. How might such an explanation go? With only a few additions, we already have the ingredients for the requisite non-vindicating explanation: in particular, a combination of the ideas motivating the Special Interests and the Modal Strategies explain why we treat the reason to believe in accord with the evidence as universal, despite the fact that it isn't. Let me explain.

To begin, recall what we found wanting about each of the Special Interests and Modal Strategies. The Special Interests Strategy failed because, although it seemed plausible to suppose that, for a wide range of propositions, agents have an interest in the truth about those propositions, it wasn't plausible that agents have a fully general interest in truth. As we saw, this gap, between agents' manifest interest in believing truly about a wide range of propositions and their much less manifest interest in (simply) believing truly is what makes the Special Interests strategy incapable of grounding the universality of the reason to believe in accord with the evidence. But focus for the moment on the claim that the Special Interests Strategy is obviously correct to make: that agents have, for a wide range of propositions, an interest in believing truly about those propositions. Call this claim Wide Interest in Truth. What about the Modal Strategy? The Modal Strategy failed because it was incapable of establishing, what it was required to establish, that each and every proposition is such that, were it falsely believed by some agent, the agent's so believing would initiate a run-on effect that made it more likely that the agent would believe falsely about some proposition believing the truth about which would directly promote the satisfaction of the agent's interests at a time. As we saw, this claim required an incredibly strong hypothesis about the holism of belief formation we don't have any positive reason to accept. But, again, focus for the moment on the claim that the Modal Strategy was obviously correct to make: that there is a wide range of propositions such that believing truly about those propositions will either directly promote the satisfaction of an agent's interests or affect the likelihood of her believing truly about still further propositions believing truly about which in turn promote the satisfaction of an agent's interests. Call this claim wide truth-interest connection.

Taken together, Wide Interest in Truth and Wide Truth-Interest Connection make it completely unsurprising that we treat the reason to believe in accord with the evidence as universal, despite the fact that, if instrumentalism of the kind I am urging here is correct, it isn't. This is because, given Wide Interest in Truth and Wide Truth-Interest Connection, the overwhelming majority of cases we encounter will be ones where there is a reason to believe in accord with the evidence. This doesn't mean the reason is universal. Instead, what it means is that, because of Wide Interest in Truth and Wide Truth-Interest Connection, the reason to believe in accord with the evidence 
is widespread. Indeed, saying that it's widespread might be understating things. For notice that only quite exceptional cases, such as cases where an agent's interests would not in any way be promoted by believing truly, will be ones where there an agent genuinely lacks a reason to believe in accord with the evidence. Such cases are, to borrow a phrase from Juvenal, very like black swans. But their relative rarity, or instead the fact that, in our ordinary lives we do not encounter them, does not mean that they do not exist. It only means that, like early Dutch explorers, we shall be very surprised when they show up.

The instrumentalist who answers the Universality Challenge in this way thus offers a non-vindicating, or debunking explanation of why it is that we think the reason to believe in accord with the evidence is universal. The reason isn't universal, but we're inclined to think that it is, and treat it as if it were, because the cases we are likely to encounter, the ones we do in fact encounter, are all ones where the reason is present. (1) is false, but we have the strong, entirely explicable, intuition that it's true.

There's an obvious question to ask about this non-vindicating explanation of the universality of the reason to believe in accord with the evidence. It's this: Why, when we encounter a case that looks like it might be a candidate for a case where the reason does not exist, are we inclined to insist that, nevertheless, in this case there is a reason to believe in accord with the evidence? After all, if this non-vindicating explanation is correct, there really are cases where the reason does not exist. Why, then, when a plausible candidate for such a case presents itself, are we inclined to say that there still is a reason to believe in accord with the evidence ${ }^{31}$ My answer is twofold.

First, and here I'm drawing on recent work by Sinan Dogramaci, our epistemic evaluative practice - the practice of appraising and evaluating our own and others' beliefs_-plays a particular role in our lives. Dogramaci argues, persuasively in my view, that the function of our practice of epistemic evaluation is to coordinate around epistemic rules coordination around which serves our collective epistemic goals and, at the limit, allows other agents to serve as "epistemic surrogates" for ourselves. ${ }^{32}$ The idea, then, is that this fact, that our epistemic evaluative practice serves a coordinative function, explains why we aren't inclined to countenance apparent cases where an agent lacks a reason to believe in accord with the evidence. For, by its very nature, a case where an agent lacks a reason to believe in accord with the evidence will be a case where the agent has only idiosyncratic reasons for her belief: reasons that we have no reason to expect other agents will be in a position to share. But in such cases the coordinative function of epistemic thought and talk is undermined: when we say that the agent's belief is rational, we ordinarily mean to indicate that it would be rational for anyone in her position. But if it's truly a case where the agent lacks a reason to believe in accord with her evidence, yet nevertheless believes rationally, then it's not true that the relevant belief would be rational for just anyone. So, insofar as part of our practice of epistemic evaluation is this commitment to coordination, we will not

\footnotetext{
31 Kelly (2003) takes this to be a point against instrumentalism.

32 Dogramaci (2012, p. 15). In Dogramaci (2013) he goes further: according to the argument there, epistemic communism - the view that the function of our epistemic evaluative practice is to coordinative-supports a kind of epistemic conventionalism. Here I lack the space to address these arguments, and note only that the instrumentalist will disagree with this deflationary account of the requirements of epistemic rationality.
} 
be inclined to countenance exceptional cases where agents lack a reason to believe in accord with the evidence since countenancing such cases appears to undermine the coordinative function of our epistemic thought and talk.

Second, and more decisively in my view, cases that look like cases where there is no reason for an agent to believe in accord with her evidence will often, on further inspection, turn out to be cases where there really is, after all, such a reason. In other words, what looks at first to be a black swan will often turn out to be just a muddy, more ordinary bird. This is clearest, perhaps, if we think about the wide truthinterest connection. When we learned that Wide truth-interest connection was true, we didn't just learn that there are a range of propositions believing the truth about which is directly promotive of an agent's interests, whatever their content. We also learned that, given some reasonable assumptions about the holism of belief formation (though not the exceptionally strong assumption the Modal Strategy required), there are an enormous range of propositions believing the truth about which is indirectly promotive of an agent's interests. There are therefore two general, and a huge number of particular, ways we can be mistaken about the claim that, in this particular case, there isn't a reason for an agent to believe in accord with the evidence. First, we might be wrong because we fail to identify some actual interest of the agent's that is promoted by believing in accord with her evidence. Second, we might be wrong because we fail to identify some proposition believing the truth about which would be affected by believing some further proposition believing the truth about which would be affected [...] and so on, until we come to the proposition in question. Given that the possibility of our error in identifying whether either or both these two conditions hold is overwhelmingly more likely than the alternative-that this really is a case where the agent lacks a reason to believe in accord with the evidence-it seems even the most modest amount of epistemic humility would recommend against concluding, when faced with some apparent case where the reason does not exist, that it is in fact a case where the reason does not exist.

Let me make one final remark before considering where this leaves us. The situation of the epistemic instrumentalist who answers Universality Challenge in this way is analogous to the situation of the moral instrumentalist who gives up her ambitions to account for the universality of the reason to do what morality requires. In recent work, David Sobel has argued forcefully that moral instrumentalism (his brand of instrumentalism goes by the name "subjectivism") has the resources to explain why it is that we might have the intuition that the reason to be moral is a universal reason. ${ }^{33}$ According to Sobel, the moral instrumentalist can offer a non-vindicating explanation of that intuition: that is, she can offer an explanation for why we - or at least, some of us-might have the (strong) intuition that the reason to be moral is universal. According to his suggestion, we have that intuition because of facts about the nature of our practice of moral evaluation, including the fact that, most of the time, most agents will have a reason to be moral. In other words, the reason is widespread. And that is precisely what I am urging the epistemic instrumentalist do: she should explain, with the resources already available to her, why we might have the intuition that always,

33 Sobel (2017). 
everywhere, regardless of what they care about, all agents have an epistemic reason to believe in accord with their evidence. The intuition is explained by the fact that, even were it the case that this reason to depend on agents' idiosyncratic interests, we would expect the practice of epistemic evaluation to look much the same as it does, and in particular we would expect it to treat that reason as if it were present, even in cases where it might not appear to be.

\section{Concluding remarks: moving epistemic intrinsicalists}

So: that is what I think the instrumentalist should say. It's unlikely to convince dyedin-the-wool intrinsicalists. But it might move some. In particular, it might move intrinsicalists whose concern was not with the universality of the reason to believe in accord with the evidence but was instead with holding on to the ordinary, everyday practice of epistemic evaluation. It does seem to me that there are such intrinsicalists. With some hesitation, I think Thomas Kelly might be such a intrinsicalist. He has argued, in several places, against instrumentalism of the sort that concerns us here. ${ }^{34}$ But Kelly's arguments, with no exceptions as far as I can tell, all appeal to what, intuitively, we would be inclined to say about particular cases where an agent's interests make it the case that there is no reason for her to believe in accord with the evidence. For example, Kelly imagines a case in which an agent stumbles on (decisive) evidence to the effect that $P$, but where her interests would be better served by believing not- $P$, or by having no belief at all with respect to whether $P$. Kelly's judgment about the case, which I endorse, is that we are inclined to say that, despite her having no interest in whether $P$, or even if she has an interest better served by believing not- $P$, the agent would be irrational if she failed to believe $P$. The upshot of this, according to Kelly, is that the instrumentalist account of the reason to believe in accord with the evidence according to which it is tied essentially to agents' interests must be mistaken. After all, if the reason were so tied were, then in this case it wouldn't exist, and so it wouldn't be irrational for the agent to fail to believe $P$ : in fact, despite the fact that the evidence supports $P$, it might be rational for her to believe not- $P$ !

But we must move cautiously here, and once we have the non-vindicating explanation of the universality of the reason to believe in accord with the evidence on the table, we can see that the instrumentalist can accept Kelly's judgment about the case, at least insofar as that judgment is a matter of what we are inclined to say about the case. This is because, for the instrumentalist who takes the route I am suggesting she should take, facts about our intuitive judgments about rationality in particular cases are simply not determinative with respect to the facts about what the reasons actually are: although the two tend, on the whole, for the most part, and almost without exception, to go together (that is what the Special Interests and Modal Strategies taught us), they can pull apart (that is what the failure of the Special Interests and Modal Strategies taught us). But the fact that the deliverances of our intuitive judgments and the deliverances of the theory can pull apart doesn't mean either that our practice of epistemic evaluation - in particular, our practice of evaluating agents as epistemically irrational

${ }^{34}$ Kelly $(2007,2003)$. 
for failing to be responsive to evidence-is somehow mistaken, or that the conception of reasons that underwrites the possibility of divergence is somehow mistaken. The instrumentalist has (she thinks) good reason to think that the reason to believe in accord with the evidence depends on agents' interests, and we've just seen that we (all) have good reason to expect that the practice of epistemic evaluation will not treat the reason as depending on interests in this way. So, again with some hesitation, I think that intrinsicalists like Kelly might be persuaded to give up their intrinsicalist ambitions, at least insofar as those ambitions were motivated by a concern only with the Universality Challenge. ${ }^{35}$

Let me close with one final comment. This proposal has a whiff of fictionalism about it, but it differs in an important way from positions that ordinarily earn that label. Fictionalism about a domain of discourse (moral evaluation, say) holds that claims within that domain of discourse are systematically false. Usually, the idea is that whatever would be required in order for the relevant claims to be true (a nonnatural moral ontology, say) simply doesn't exist. The fictionalist then proceeds to explain how and to what extent it can nonetheless be useful to proceed as if the relevant claims were true. In the case of morality, fictionalists appeal, for example, to the utility of (systematically false) moral claims for regulating behavior, organizing social structures, and so on. It might appear that what I am offering here on behalf of epistemic instrumentalism is a kind of epistemic fictionalism of this sort: although claims made in the course of epistemic evaluation are systematically false, they are, to some extent, useful (perhaps for organizing behavior or coordinating thought and talk). But that is not quite right.

According to the proposal on offer here, there is no suggestion here that the claims made in the course of epistemic evaluation-epistemic discourse, if you like-are systematically false. Indeed, if as it seems the Special Interests and Modal Strategies go a long — though not the entire-way toward establishing the universality of the reason to believe in accord with the evidence, then the claims made in epistemic discourse are on the whole, for the most part, largely true. After all, as we have already seen, for the most part, most of the time, agents do have an interest in believing truly about any arbitrary proposition, either because they are directly interested in the truth of that proposition (the special interests strategy), or because believing truly about that proposition will promote some other interest of theirs (the Modal Strategy). So unlike epistemic fictionalism, the instrumentalist who takes the route I am suggesting is not committed to thinking that the claims made in epistemic discourse (e.g., "that belief is irrational") are systematically false. Quite the contrary: most of the time, such claims will be true.

\section{Summary}

Unlike intrinsicalists, instrumentalists appear to face an explanatory puzzle: How is it that the reason to believe in accord with the evidence is universal, despite depending,

\footnotetext{
35 Of course, intrinsicalists and instrumentalists are free to disagree on other grounds. And here, in this paper, I haven't offered any positive argument in favor of instrumentalist against its intrinsicalist competitor.
} 
as instrumentalists say it does, on agents' possibly idiosyncratic interests. I've argued that two strategies for solving this puzzle do not work. Instrumentalists can't answer by appealing to special epistemic interests. And they can't answer by appealing to the role played by true beliefs in promoting our interests, whatever those interests might be. Intrinsicalists will, of course, welcome this result: just more arrows in their antiinstrumentalist quiver. But I've suggested there's a way forward for the instrumentalist. The way forward is to focus her efforts not on offering a vindicating explanation of the universality of the reason to believe in accord with the evidence, but a non-vindicating explanation of the same. And this latter task is, I've argued, one the instrumentalist can accomplish.

Acknowledgments I thank students in my Spring 2016 graduate seminar on epistemic normativity, audiences at the University of Chicago, Virginia Tech, and the CNY Ethics Reading Group, as well as two anonymous referees for their feedback on this paper. I also thank Ben Bradley, Nykki Dular, Nikki Fortier, Ram Neta, Hille Paakkunainen, and David Sobel for fruitful discussions on the topic.

\section{References}

Achinstein, P. (2003). The book of evidence. Oxford: Oxford University Press.

Alston, W. (2005). Beyond "justification": Dimensions of epistemic evaluation. Ithaca: Cornell University Press.

Behrends, J., \& DiPaolo, J. (2011). Finlay and Schroeder on promoting a desire. Journal of Ethics and Social Philosophy, pp. 1-6.

BonJour, L. (1985). The structure of empirical knowledge. Cambridge: Harvard University Press.

Brogaard, B. (2009). The trivial argument for epistemic value pluralism, or, how i learned to stop caring about truth. In A. Haddock, A. Millar, \& D. Pritchard (Eds.), Epistemic value (pp. 284-305). Oxford: Oxford University Press.

Coates, D. J. (2014). An actual-sequence theory of promotion. Journal of Ethics and Social Philosophy, 8, $1-7$.

Cowie, C. (2014). In defence of instrumentalism about epistemic normativity. Synthese, 191(16), 40034017.

Cuneo, T. (2007). The normative web: An argument for moral realism. Oxford: Oxford University Press.

David, M. (2001). Knowledge, truth, and duty. New York: Oxford University Press.

Dellsén, F., \& Sharadin, N. (unpublished). Promotion as contrastive increase in expected fit. Unpublished manuscript.

DiPaolo, J., \& Behrends, J. (2015). Reason to promotion inferences. Journal of Ethics and Social Philosophy, pp. 1-9.

Dogramaci, S. (2012). Reverse engineering epistemic evaluations. Philosophy and Phenomenological Research, 84(3), 513-530.

Dogramaci, S. (2013). Communist conventions for deductive reasoning. Noûs, 49(4), 776-799.

Dreier, J. (2015). Can reasons fundamentalism answer the normative question? In G. Björnsson, C. Strandberg, R. F. Olinder, J. Eriksson, \& F. Bjorklund (Eds.), Motivational Internalism. Oxford: Oxford University Press.

Enoch, D. (2006). Agency, schmagency: Why normativity won't come from what is constitutive of action. Philosophical Review, 115, 169-198.

Enoch, D. (2011). Schmagency revisited. In M. Brady (Ed.), New Waves in Metaethics (pp. 208-233). New York: Palgrave Mcmillan.

Ferrero, L. (2009). Constitutivism and the inescapability of agency. In R. Shafer-Landau (Ed.), Oxford Studies in Metaethics (Vol. 4, pp. 303-333). Oxford: Oxford University Press.

Foley, R. (1987). The theory of epistemic rationality. Cambridge: Harvard University Press.

Frost, K. (2014). On the very idea of direction of fit. Philosophical Review, 123(4), 429-484.

Grimm, S. R. (2008). Epistemic goals and epistemic values. Philosophy and Phenomenological Research, 77, 725-744. 
Grimm, S. R. (2009). Epistemic normativity. In M. Haddock \& D. Pritchard (Eds.), Epistemic value. New York: Oxford University Press.

Katsafanas, P. (2011). Deriving ethics from action: A nietzschean version of constitutivism. Philosophy and Phenomenological Research, 83, 620-660.

Kelly, T. (2003). Epistemic rationality as instrumental rationality: A critique. Philosophy and Phenomenological Research, 66(3), 612-640.

Kelly, T. (2007). Evidence and normativity: Reply to Leite. Philosophy and Phenomenological Research, 75(2), 465-474.

Kornblith, H. (1993). Epistemic normativity. Synthese, 94(3), 357-376.

Kornblith, H. (2002). Knowledge and its place in nature. Oxford: Oxford University Press.

Korsgaard, C. (1999). Self-constitution in the ethics of plato and kant. Journal of Ethics, 3, 1-29.

Korsgaard, C. (2009). Self-constitution: Agency, identity, and integrity. Oxford: Oxford University Press.

Kvanvig, J. (2003). The value of knowledge and the pursuit of understanding. Cambridge: Cambridge University Press.

Kvanvig, J. (2005). Truth is not the primary epistemic goal. In M. Steup \& E. Sosa (Eds.), Contemporary debates in epistemology (pp. 285-296). Malden: Blackwell Publishers.

Lin, E. (2016). Simple probabilistic promotion. Philosophy and Phenomenological Research.

Lynch, M. P. (2009). The values of truth and the truth of values. In A. Haddock, A. Millar, \& D. Pritchard (Eds.), Epistemic value (pp. 225-242). Oxford: Oxford University Press.

Nolfi, K. (2015). Why we should care about the epistemic status of our beliefs. unpublished.

Nozick, R. (1993). The nature of rationality. Princeton: Princeton University Press.

Olson, J. (2011). Error theory and reasons for belief. In A. Reisner \& A. Steglich-Petersen (Eds.), Reasons for belief. Cambridge: Cambridge University Press.

Papineau, D. (1999). Normativity and judgment. Proceedings of the Aristotelian Society, 73(supplementary), $17-41$.

Papineau, D. (2009). There are no norms of belief. unpublished.

Parfit, D. (2011). On what matters (Vol. II). Oxford: Oxford University Press.

Rosati, C. S. (2003). Agency and the open question argument. Ethics, 113(3), 490-527.

Schroeder, M. (2007). Slaves of the passions. Oxford: Oxford University Press.

Sharadin, N. (2015a). Problems for probabilism about promotion and an alter native. Philosophical Studies, 172(5), 1371-1386.

Sharadin, N. (2015b). Reasons and promotion. Philosophical Issues: A supplement to Nous, 25(1), 98-122.

Sharadin, N. (2016). Checking the neighborhood: A reply to DiPaolo and Behrends on promotion. Journal of Ethics and Social Philosophy.

Silverstein, M. (2015). The shmagency question. Philosophical Studies, 172(5), 1127-1142.

Smith, M. (2013). A constitutivist theory of reasons: Its promise and parts. Law, Ethics, and Philosophy, 1, 9-30.

Snedegar, J. (2014). Contrastive reasons and promotion. Ethics, 124(1), 39-63.

Sobel, D. (2017). From value to valuing: Towards a defense of subjectivism. Oxford: Oxford University Press.

Steglich-Petersen, A. (2006). No norm needed: On the aim of belief. The Philosophical Quarterly, 56(225), 499-516.

Steglich-Petersen, A. (2008). Does doxastic transparency support evidentialism. Dialectica, 62(4), 541-547.

Stitch, S. (1990). The fragmentation of reason: Preface to a pragmatic theory of cognitive evolution. Cambridge: MIT Press.

Street, S. (2008). Constructivism about reasons. In R. Shafer-Landau (Ed.), Oxford studies in metaethics. Oxford: Oxford University Press.

Street, S. (2009). Evolution and the normativity of epistemic reasons. Canadian Journal of Philosophy, $39(1), 213-248$.

Streumer, B. (2013). Can we believe the error theory? Journal of Philosophy, 110(4), 194-212.

Tiffany, E. (2011). Why be an agent? Australasian Journal of Philosophy, 90(2), 223-233.

Velleman, D. (1989). Practical Reflection. Princeton: Princeton University Press.

Velleman, D. (2000). The possibility of practical reason. The possibility of practical reason (pp. 170-199). Oxford: Oxford University Press.

Wedgwood, R. (2007). The nature of normativity. Oxford: Oxford University Press. 